\title{
Photodynamic Therapy for Cholangiocarcinoma
}

\author{
Jayant P. Talreja and Michel Kahaleh \\ Division of Gastroenterology and Hepatology, University of Virginia, Charlottesville, VA, USA
}

Cholangiocarcinoma is the primary malignancy arising from the biliary epithelium, and it presents as jaundice, cholestasis, and cholangitis. Over 50 percent of patients present with advanced-stage disease, and the prognosis is poor with the survival measured in months even after biliary decompression. Palliative management has become the standard of care for unresectable disease, and this involves an endoscopic approach. Photodynamic therapy (PDT) involves the administration of a photosensitizer followed by local irradiation with laser therapy. The use of PDT for palliation of bile-duct tumors has produced promising results. Several studies conducted in Europe and the United States have shown that PDT produces a marked improvement in the symptoms of cholestasis, survival, and quality of life. This chapter summarizes the principle of PDT, the technique employed, and the published experience regarding PDT for cholangiocarcinoma. (Gut Liver 2010;4(Suppl. 1):S62-66)

Key Words: Cholangiocarcinoma; Photodynamic therapy; Biliary cancer

\section{INTRODUCTION}

Cholangiocarcinoma is a malignancy that arises from the epithelial cells of the biliary tree. It can affect the intrahepatic and extrahepatic bile ducts and is associated with significant morbidity and mortality. ${ }^{1}$ Tumor formation appears to be the result of an underlying chronic inflammatory state of the biliary tract. There are multiple possible predisposing conditions, which include primary sclerosing cholangitis, intrahepatic stones and choledocholithiasis, choledochal cysts, liver flukes, and prior exposure to thorium dioxide. ${ }^{2-9}$
The average 5-year survival rate of patients with cholangiocarcinoma is $5-10 \% .{ }^{10}$ The incidence of cholangiocarcinoma is increasing ${ }^{11}$ and is currently thought to be one to two cases per 100,000 patients in the United States, with the majority of patients being predominantly male and older than 65 years of age. ${ }^{10}$ The only hope for cure is surgical resection. Even after curative resection, the 5-year survival rate is only $30-40 \% .{ }^{12-14}$ Unfortunately, greater than $80 \%$ of patients present at an unresectable stage, ${ }^{11}$ with a median survival time of 3-6 months from the time of diagnosis. ${ }^{15}$ These patients require palliative management.

Surgical decompression of the biliary tract involves a hepatico-jejunostomy, which has a 30 day post-operative mortality rate between $7 \%$ and $24 \% .{ }^{16-19}$ Recovery time is a limiting factor in quality of life improvement in a majority of patients who undergo surgery. ${ }^{20-22}$ Presently, biliary decompression is most frequently accomplished through endoscopic biliary stent placement. This has been shown to relieve obstructive jaundice, but has not been shown to improve survival. ${ }^{11}$ The addition of chemotherapy to biliary decompression has been largely unsuccessful. ${ }^{23}$ Various chemotherapeutic agents have been studied with overall minimal improvement in survival. ${ }^{24-26}$ The survival benefit of palliative radiation therapy is considered controversial. ${ }^{10}$ It has been associated with an increased incidence of cholangitis, gastroduodenitis, and longer hospitalizations. ${ }^{27-29}$ Concurrent chemotherapy with radiation therapy, including helical tomotherapy intensity modulated radiotherapy and capecatibine, in conjunction with photodynamic therapy (PDT) has been shown to be well tolerated in patients with hilar cholangiocarcinoma. ${ }^{30,31}$ Wiedmann et al. ${ }^{32}$ published their results using PDT as a neoadjuvant treatment for hilar cholangio-

\footnotetext{
Correspondence to: Michel Kahaleh

Pancreatico-Biliary Services, Digestive Health Center, Box 800708, University of Virginia Health System, Charlottesville, VA 22908-0708, USA

Tel: +1-434-243-9259, Fax: +1-434-924-0491, E-mail: mk5ke@virginia.edu

DOI: $10.5009 /$ gnl.2010.4.S1.S62
} 
carcinoma. Seven patients were treated and underwent surgery after a median period of 6 weeks (range, 3-44 weeks). In all patients tumor free resection margins were achieved with a 1-year recurrence free survival rate of $83 \%$. Neoadjuvant PDT did not increase the rate of surgical complications and was well tolerated. Additionally, proximal obstruction of the bile ducts by malignant tissue can prevent successful endoscopic stenting. Photodynamic therapy has recently been introduced to circumvent this problem. ${ }^{11}$

\section{PRINCIPLE OF PHOTODYNAMIC THERAPY}

This therapy includes the use of, a photosensitizing agent administered before the photoradiation process can occur. ${ }^{33}$ Photofrin (porfimer sodium; Axcan Pharma Inc., Mont-Saint Hilaire, Canada) has a selective nature and is preferentially retained by neoplastic tissue. ${ }^{33}$ At a specific wavelength of light, laser application begins the activation process by transforming the drug from its neutral ground state into its excited state. In the presence of oxygen, cytotoxic radical species are formed, which destroy dysplastic cells by directly inducing apoptosis and tumor necrosis. Local vascular channels are also affected. ${ }^{34,35}$ PDT was demonstrated to reduce xenografted human cholangiocarcinoma tumor volume by $60 \%$ in a mouse model. ${ }^{36}$ PDT has been shown to have a significant survival benefit in patients with unresectable cholangiocarcinoma as well as a significant improvement in the quality of life after PDT and stenting. ${ }^{37,38}$

Though other photosensitizers are now available, porfimer sodium is the most studied and the only photosensitizer approved by the FDA.

\section{STAGING AND TISSUE DIAGNOSIS}

All patients must have clinical and radiological features of cholangiocarcinoma. Staging can be performed by computed tomography (CT) or magnetic resonance imaging (MRI). Staging can be performed with CT and/or MRI. ${ }^{37}$ Resectability is usually defined according to the criteria of Vauthey and Blumgart. ${ }^{39}$

Bismuth classification should be documented for all patients. ${ }^{1}$ In our experience and others, ${ }^{37,40}$ definitive pathological diagnosis of cholangiocarcinoma is established in approximately $60 \%$ of cases. ${ }^{37,40}$

\section{TECHNIQUE}

Each patient undergoes a detailed educational process on PDT after which informed consent is obtained. Pa- tients treated with PDT receive Porfimer sodium (Photofrin; Axcan Pharma Inc.) at a dosage of $2 \mathrm{mg} / \mathrm{kg}$ body weight intravenously 48 hours before laser activation.

Endoscopic retrograde cholangiography (ERC) is performed using a large channel duodenoscope (TJF-140, TJF-160, and TJF-160VF; Olympus America, Center Valley, PA, USA). After cannulation into the biliary tract, a cholangiogram is performed to help define the anatomic distribution of malignant tissue and the extent of disease within the biliary ducts. Careful opacification of the dilated segments is performed selectively. Next, selective bougie and balloon dilation of the stricture(s) to be treated is performed to facilitate diffuser placement within the malignant stricture.

Photodynamic therapy is delivered through a 3.0-m length fiber with a $2.5-\mathrm{cm}$-long cylindrical diffuser at its distal end (Pioneer Optics, Windsor Locks, CT, USA). The diffuser can be inserted into a $10 \mathrm{~F}$ sheath of a plastic stent delivery system and placed at the level of the stricture being treated. ${ }^{37}$ Alternatively, our group has been using the single operator cholangioscopy (SOC) as a platform to administer PDT (Spyglass; Boston Scientific, Natick, MA, USA). ${ }^{40}$

A diode laser system (InGaAIP Laser Diode; Diomed Inc., Andover, MA, USA) with a maximum power output of $2,000 \mathrm{~mW}$ and a wavelength of $633 \pm 3 \mathrm{~nm}$ is used as a light source.

Photoactivation is performed at $630 \mathrm{~nm}$ with a light dose of $180 \mathrm{~J} / \mathrm{cm}^{2}$, fluence of $0.250 \mathrm{~W} / \mathrm{cm}^{2}$ and irradiation time of 750 seconds. Multiple segments can be treated at the discretion of the endoscopist. When tumor length exceeds the maximal diffuser length, overlap of treated areas should be avoided by a stepwise pull-back of the fiber under fluoroscopic guidance. Placement of endoprostheses is performed systematically after the photodynamic treatment to prevent cholangitis. ${ }^{37}$

PDT is typically repeated at 3-month intervals at which time all stents should be replaced; stents are exchanged earlier in the case of premature occlusion or migration to maintain optimal decompression. All patients should receive peri-operative antibiotic prophylaxis. Post-operatively, patients treated with PDT are advised to remain out of direct sunlight since Porfimer sodium may cause prolonged photosensitivity lasting 30-90 days. ${ }^{41}$

\section{REVIEW OF THE LITERATURE}

There have been several uncontrolled reports that suggest that PDT can provide for a survival benefit (Table 1). In 2003, Ortner et al. $^{33}$ conducted the first randomized controlled trial comparing survival between biliary stent- 
Table 1. Table Comparing Studies Performed by Using ERCP with PDT with Photofrin Sodium for Palliation of Cholangiocarcinoma

\begin{tabular}{|c|c|c|c|c|c|c|c|}
\hline Study & Year & $\begin{array}{l}\text { No. of } \\
\text { patients }\end{array}$ & Study type & $\begin{array}{l}\text { Median TB before } \\
\text { and after PDT }\end{array}$ & $\begin{array}{l}\text { Mean PDT } \\
\text { sessions } \\
\text { (range) }\end{array}$ & $\begin{array}{l}\text { Median } \\
\text { survival, } \\
\text { mo }\end{array}$ & $\begin{array}{c}\text { Adverse events } \\
\text { phototoxicity, } \\
\text { cholangitis }\end{array}$ \\
\hline Ortner et al. ${ }^{41}$ & 1998 & 9 & Single arm & $18.6>6$ & $1.5(1-2)$ & 14.6 & 1 (11\%), 0 (0\%) \\
\hline Berr et al. ${ }^{36}$ & 2000 & 23 & Single arm & $11.2>1.1$ & $3(1-5)$ & 11.1 & 3 (13\%), 8 (35\%) \\
\hline Rumalla et al. ${ }^{48}$ & 2001 & 6 & Single arm & $2.7>1.3$ & $2.3(1-2)$ & $>6$ & $2(33 \%), 2(33 \%)$ \\
\hline Dumoulin et al. ${ }^{49}$ & 2003 & 24 & Single arm & $13.3>2.6$ & $1-2$ & 9.9 & $2(8 \%), 5(21 \%)$ \\
\hline Ortner et al. ${ }^{33}$ & 2003 & 20 & Randomized & NA (decreased) & $2.4(1-5)$ & 16.4 & $2(10 \%), 5(25 \%)$ \\
\hline Ortner et al. ${ }^{33}$ & 2003 & 31 & Nonrandomized & $11.8>3.1$ & $1.5(1-4)$ & 14.2 & $3(10 \%), 6(19 \%)$ \\
\hline Harewood et al. ${ }^{50}$ & 2005 & 8 & Single arm & $7.7>1.1$ & $2(1-5)$ & 9.2 & $2(25 \%), 2(25 \%)$ \\
\hline Witzigmann et al. ${ }^{51}$ & 2006 & 68 & Single arm & NA (decreased) & $2(1-6)$ & 12 & 8 (12\%), 38 (56\%) \\
\hline Prasad et al. ${ }^{44}$ & 2007 & 25 & Single arm & $6.1>3.5$ & $1.6(1-4)$ & 13.4 & $1(4 \%), 2(8 \%)$ \\
\hline Kahaleh et al. ${ }^{37}$ & 2008 & 19 & Comparative & $6.3>3.5$ & $1.6(1-3)$ & 16.2 & 3 (16\%), 7 (37\%) \\
\hline
\end{tabular}

ERCP, endoscopic retrograde cholangiopancreatography; PDT, photodynamic therapy; TB, total bilirubin; NA, not available.

ing alone vs biliary decompression combined with photodynamic therapy. After enrolling 39 patients in the study, a median survival of 493 days $(n=20)$ was noticed in the group treated with PDT and stenting vs. a median survival of 98 days $(n=19)$ in the stent-alone group $(\mathrm{p}<$ 0.0001 ). The trial was terminated prematurely as continued data collection and randomization was thought to be ethically unacceptable. This study was criticized since only patients failing conventional ERC were enrolled in the study, making a repeat ERC indispensable which might account for the benefit attributed to PDT. Another randomized study by Zoepf et al. ${ }^{38}$ showed similar improvement of survival time in the PDT group (21 vs 7 months). Three recent reviews that analyzed the contribution of photodynamic therapy to the treatment of cholangiocarcinoma all confirmed these data. ${ }^{11,42,43}$

In 2007, Prasad et al. ${ }^{44}$ found that patients with unresectable cholangiocarcinoma without a visible mass benefited from early treatment with PDT. They described a technique for photodynamic therapy using percutaneous biliary access. Patients that failed biliary cannulation or those with pre-existing biliary drains were successfully treated using this method. The percutaneous biliary drain was replaced with an $8 \mathrm{~F}$ vascular sheath over a guidewire. PDT was administered by fluoroscopically guided placement of the cylindrical diffusing fiber. After the treatment was completed, a standard $10 \mathrm{Fr}$ biliary drain was placed to facilitate biliary drainage.

In 2008 , our group compared stenting alone vs combination therapy of stenting and photodynamic therapy. ${ }^{37}$ Kaplan-Meier analysis demonstrated improved survival in the PDT group compared with the stent-alone group (16.2 vs 7.4 months, $\mathrm{p}<0.004)$. Mortality in the PDT group at 3, 6, and 12 months was $0 \%, 16 \%$, and $56 \%$, respectively. The corresponding mortality in the stent group was $28 \%, 52 \%$, and $82 \%$, respectively. The difference between the two groups was statistically significant at 3 and 6 months, but not at 12 months. Although it was not entirely clear whether the benefit was directly related to PDT or the number of endoscopic retrograde cholangiopancreatography (ERCP) sessions, this study helped to strengthen the findings published by Ortner et al. in 2003. ${ }^{33}$ Importantly, adverse effects in the PDT group were minor, largely related to self-limiting phototoxicity.

\section{FUTURE DIRECTION}

Successful PDT under cholangioscopic guidance has been previously reported by Ortner et al. ${ }^{33,41}$ Although past efforts at cholangioscopy were generally time consuming and technically demanding, the development of SOC has allowed the procedure to become more feasible. SOC is a platform initially designed to enhance diagnostic accuracy during ERCP by allowing guided biopsy. ${ }^{45,46}$

Recently, our group compared patients who underwent PDT alone with patients who underwent PDT using SOC. $^{40}$ A total of forty-five patients (24 male, aged $67.3 \pm 10.6$ years) were treated with PDT during a fiveyear period. Thirty-two patients were treated with PDT alone, and 13 patients were treated with PDT using SOC. The two groups did not differ significantly in regards to age, gender, serum bilirubin, or MELD score. No significant difference existed between the two groups regarding the number of ERCP sessions $(p=0.71)$, the number of PDT sessions $(\mathrm{p}=0.36)$ or the PDT procedure time $(\mathrm{p}=0.76)$. The median fluoroscopy time was 21.1 minutes in the PDT only group and 11.1 minutes in the PDT using SOC group $(p<0.0001)$. Median survival for the PDT only group was 200 days, and median survival for the 
PDT using SOC group was 386 days $(p=0.45)$. There was no significant difference in total adverse affects between the groups $(p=1.0)$. SOC permits targeted therapy during PDT and can be successfully performed without adverse events while simultaneously reducing exposure to radiation.

In the near future novel therapeutic approaches such as targeted molecular therapies may be used in conjunction with PDT to improve outcomes. Finally, alternative photosensitizers are needed that provided deeper tumoricidal tissue penetration, shorter duration of phototoxicity, and more rapid onset. ${ }^{47}$

\section{CONCLUSION}

In summary, the majority of patients with cholangiocarcinoma present with advanced, unresectable disease and treatment options are generally limited to palliation. Photodynamic therapy in conjunction with stenting has shown very promising outcomes; Further multicenter, randomized, prospective controlled trials are needed to confirm the benefit of PDT and stenting compared to stenting alone, to confirm the role of SOC in PDT, and to identify the optimal treatment regimen in these patients in order to improve survival and quality of life.

\section{REFERENCES}

1. Ahrendt SA, Nakeeb A, Pitt HA. Cholangiocarcinoma. Clin Liver Dis 2001;5:191-218.

2. Bergquist A, Ekbom A, Olsson R, et al. Hepatic and extrahepatic malignancies in primary sclerosing cholangitis. $\mathrm{J}$ Hepatol 2002;36:321-327.

3. Haswell-Elkins MR, Mairiang E, Mairiang P, et al. Crosssectional study of Opisthorchis viverrini infection and cholangiocarcinoma in communities within a high-risk area in northeast Thailand. Int J Cancer 1994;59:505-509.

4. Jang KT, Hong SM, Lee KT, et al. Intraductal papillary neoplasm of the bile duct associated with Clonorchis sinensis infection. Virchows Arch 2008;453:589-598.

5. Khan SA, Thomas HC, Davidson BR, Taylor-Robinson SD. Cholangiocarcinoma. Lancet 2005;366:1303-1314.

6. Kim YT, Byun JS, Kim J, et al. Factors predicting concurrent cholangiocarcinomas associated with hepatolithiasis. Hepatogastroenterology 2003;50:8-12.

7. Kubo S, Kinoshita H, Hirohashi K, Hamba H. Hepatolithiasis associated with cholangiocarcinoma. World J Surg 1995; 19:637-641.

8. Lesurtel M, Regimbeau JM, Farges O, Colombat M, Sauvanet A, Belghiti J. Intrahepatic cholangiocarcinoma and hepatolithiasis: an unusual association in Western countries. Eur J Gastroenterol Hepatol 2002;14:1025-1027.

9. Rubel LR, Ishak KG. Thorotrast-associated cholangiocarcinoma: an epidemiologic and clinicopathologic study. Cancer 1982;50:1408-1415.
10. Anderson CD, Pinson CW, Berlin J, Chari RS. Diagnosis and treatment of cholangiocarcinoma. Oncologist 2004;9: 43-57.

11. Gao F, Bai Y, Ma SR, Liu F, Li ZS. Systematic review: photodynamic therapy for unresectable cholangiocarcinoma. J Hepatobiliary Pancreat Sci 2010;17:125-131.

12. Jarnagin WR, Shoup M. Surgical management of cholangiocarcinoma. Semin Liver Dis 2004;24:189-199.

13. Lazaridis KN, Gores GJ. Cholangiocarcinoma. Gastroenterology 2005;128:1655-1667.

14. Neuhaus P, Jonas S, Bechstein WO, et al. Extended resections for hilar cholangiocarcinoma. Ann Surg 1999; 230:808-818.

15. Wiedmann M, Berr F, Schiefke I, et al. Photodynamic therapy in patients with non-resectable hilar cholangiocarcinoma: 5-year follow-up of a prospective phase II study. Gastrointest Endosc 2004;60:68-75.

16. Chaudhary A, Dhar P, Tomey S, Sachdev A, Agarwal A. Segment III cholangiojejunostomy for carcinoma of the gallbladder. World J Surg 1997;21:866-870.

17. Havlik R, Sbisa E, Tullo A, et al. Results of resection for hilar cholangiocarcinoma with analysis of prognostic factors. Hepatogastroenterology 2000;47:927-931.

18. Kapoor VK, Pradeep R, Haribhakti SP, et al. Intrahepatic segment III cholangiojejunostomy in advanced carcinoma of the gallbladder. Br J Surg 1996;83:1709-1711.

19. Lai EC, Tompkins RK, Mann LL, Roslyn JJ. Proximal bile duct cancer. Quality of survival. Ann Surg 1987;205:111118.

20. Blom D, Schwartz SI. Surgical treatment and outcomes in carcinoma of the extrahepatic bile ducts: the University of Rochester experience. Arch Surg 2001;136:209-215.

21. Figueras J, Llado L, Valls C, et al. Changing strategies in diagnosis and management of hilar cholangiocarcinoma. Liver Transpl 2000;6:786-794.

22. Baer HU, Stain SC, Dennison AR, Eggers B, Blumgart LH. Improvements in survival by aggressive resections of hilar cholangiocarcinoma. Ann Surg 1993;217:20-27.

23. van Groeningen CJ. Intravenous and intra-arterial chemotherapeutic possibilities in biliopancreatic cancer. Ann Oncol 1999;10 Suppl 4:305-307.

24. Ducreux M, Rougier P, Fandi A, et al. Effective treatment of advanced biliary tract carcinoma using 5-fluorouracil continuous infusion with cisplatin. Ann Oncol 1998;9: 653-656.

25. Choi CW, Choi IK, Seo JH, et al. Effects of 5-fluorouracil and leucovorin in the treatment of pancreatic-biliary tract adenocarcinomas. Am J Clin Oncol 2000;23:425-428.

26. Patt YZ, Jones DV Jr, Hoque A, et al. Phase II trial of intravenous flourouracil and subcutaneous interferon alfa- $2 \mathrm{~b}$ for biliary tract cancer. J Clin Oncol 1996;14:2311-2315.

27. Khan SA, Davidson BR, Goldin R, et al. Guidelines for the diagnosis and treatment of cholangiocarcinoma: consensus document. Gut 2002;51 Suppl 6:VI1-VI9.

28. Ayaru L, Bown SG, Pereira SP. Photodynamic therapy for pancreatic and biliary tract carcinoma. Int J Gastrointest Cancer 2005;35:1-13.

29. Bowling TE, Galbraith SM, Hatfield AR, Solano J, Spittle MF. A retrospective comparison of endoscopic stenting alone with stenting and radiotherapy in non-resectable cholangiocarcinoma. Gut 1996;39:852-855. 
30. Thongprasert S. The role of chemotherapy in cholangiocarcinoma. Ann Oncol 2005;16 Suppl 2:ii93-ii96.

31. Baisden JM, Kahaleh M, Weiss GR, et al. Multimodality treatment with helical tomotherapy intensity modulated radiotherapy, capecitabine, and photodynamic therapy is feasible and well tolerated in patients with hilar cholangiocarcinoma. Gastrointest Cancer Res 2008;2:219-224.

32. Wiedmann M, Caca K, Berr F, et al. Neoadjuvant photodynamic therapy as a new approach to treating hilar cholangiocarcinoma: a phase II pilot study. Cancer 2003;97: 2783-2790.

33. Ortner ME, Caca K, Berr F, et al. Successful photodynamic therapy for nonresectable cholangiocarcinoma: a randomized prospective study. Gastroenterology 2003;125:13551363.

34. Wong Kee Song LM, Wang KK, Zinsmeister AR. MonoL-aspartyl chlorin e6 (NPe6) and hematoporphyrin derivative $(\mathrm{HpD})$ in photodynamic therapy administered to a human cholangiocarcinoma model. Cancer 1998;82:421427.

35. Henderson BW, Waldow SM, Mang TS, Potter WR, Malone PB, Dougherty TJ. Tumor destruction and kinetics of tumor cell death in two experimental mouse tumors following photodynamic therapy. Cancer Res 1985;45:572576.

36. Berr F, Wiedmann M, Tannapfel A, et al. Photodynamic therapy for advanced bile duct cancer: evidence for improved palliation and extended survival. Hepatology 2000; 31:291-298.

37. Kahaleh M, Mishra R, Shami VM, et al. Unresectable cholangiocarcinoma: comparison of survival in biliary stenting alone versus stenting with photodynamic therapy. Clin Gastroenterol Hepatol 2008;6:290-297.

38. Zoepf T, Jakobs R, Arnold JC, Apel D, Riemann JF. Palliation of nonresectable bile duct cancer: improved survival after photodynamic therapy. Am J Gastroenterol 2005;100:2426-2430.

39. Vauthey JN, Blumgart LH. Recent advances in the management of cholangiocarcinomas. Semin Liver Dis 1994;14: 109-114.

40. Talreja JP, Degaetani M, Rehan ME, Sauer BG, Kahaleh M. T1521: single operator cholangioscopy for unresectable cholangiocarcinoma treated with photodynamic therapy: what are the benefits? Gastrointest Endosc 2010;71:AB299.

41. Ortner MA, Liebetruth J, Schreiber S, et al. Photodynamic therapy of nonresectable cholangiocarcinoma. Gastroenterology 1998;114:536-542.

42. Zoepf T. Photodynamic therapy of cholangiocarcinoma. HPB (Oxford) 2008;10:161-163.

43. Ibrahim T, Kahaleh M. Photodynamic therapy: palliation and endoscopic technique in cholangiocellular carcinoma. Interv Ther Gastrointest Endosc 2010;27:423-429.

44. Prasad GA, Wang KK, Baron TH, et al. Factors associated with increased survival after photodynamic therapy for cholangiocarcinoma. Clin Gastroenterol Hepatol 2007;5: 743-748.

45. Judah JR, Draganov PV. Intraductal biliary and pancreatic endoscopy: an expanding scope of possibility. World J Gastroenterol 2008;14:3129-3136.

46. Fishman DS, Tarnasky PR, Patel SN, Raijman I. Management of pancreaticobiliary disease using a new intra-ductal endoscope: the Texas experience. World J Gastroenterol 2009;15:1353-1358.

47. Baron TH. Photodynamic therapy: standard of care for palliation of cholangiocarcinoma? Clin Gastroenterol Hepatol 2008;6:266-267.

48. Rumalla A, Baron TH, Wang KK, Gores GJ, Stadheim LM, de Groen PC. Endoscopic application of photodynamic therapy for cholangiocarcinoma. Gastrointest Endosc 2001; 53:500-504.

49. Dumoulin FL, Gerhardt T, Fuchs S, et al. Phase II study of photodynamic therapy and metal stent as palliative treatment for nonresectable hilar cholangiocarcinoma. Gastrointest Endosc 2003;57:860-867.

50. Harewood GC, Baron TH, Rumalla A, et al. Pilot study to assess patient outcomes following endoscopic application of photodynamic therapy for advanced cholangiocarcinoma. J Gastroenterol Hepatol 2005;20:415-420.

51. Witzigmann H, Berr F, Ringel U, et al. Surgical and palliative management and outcome in 184 patients with hilar cholangiocarcinoma: palliative photodynamic therapy plus stenting is comparable to $\mathrm{r} 1 / \mathrm{r} 2$ resection. Ann Surg 2006; 244:230-239. 